\title{
Comparative evaluation of morphine and fentanyl for emergence following supratentorial craniotomy
}

\author{
Hemant Bhagat, Neeru Sahni, Ishwar Bhukal, Puneet Khanna' ${ }^{1}$ Priska Bastola, \\ Parmod K. Bithal', Hari H. Dash ${ }^{2}$
}

\begin{abstract}
Background: The emergence from anaesthesia is a very crucial aspect in neurosurgical patients due to the need for evaluation of neurological status in the immediate post-operative period. The present study evaluates the emergence characteristics following administration of morphine as compared to shorter-acting opioid, fentanyl in patients undergoing supratentorial craniotomy. Methods: A total of 84 patients were included in the study. The patients either received morphine $0.1 \mathrm{mg} / \mathrm{kg}$ before induction or fentanyl $2 \mathrm{mcg} / \mathrm{kg}$ body weight at induction, I mcg/ $\mathrm{kg}$ before skin incision and at the beginning of dural closure. Doses of both opioids were repeated as judged clinically during surgery. Following surgery, the trachea was extubated after reversal of residual neuromuscular blockade, and the emergence characteristics of patients in the two groups were compared. Results: The mean time to emergence was $8.5 \pm 3.7$ min in morphine group whereas it was $7.8 \pm 5.1 \mathrm{~min}$ in fentanyl group $(P=0 . \mathrm{II})$. Conclusions: Morphine appears similar to fentanyl for facilitating early emergence in patients undergoing an elective supratentorial craniotomy.
\end{abstract}

Key words: Delayed emergence, neuroanaesthesia, opioids, tumor

\section{INTRODUCTION}

Delayed emergence after a neurosurgical procedure is a very disconcerting problem, and it leads to expensive neuroradiologic testing. It is a common belief that emergence from anaesthesia is affected by the type of opioid used intraoperatively. Although various studies have compared shorter acting opioids such as fentanyl and remifentanil, no study so far demonstrates scientifically proven rationale for using short-acting

Department of Anaesthesia and Intensive Care,

Postgraduate Institute of Medical Education and Research, Chandigarh, 'Department of Anaesthesia, AlIMS, New Delhi, ${ }^{2}$ Department of Anaesthesia and Intensive Care, Fortis Memorial Research Institute, Gurgaon, Haryana, India

\section{Address for correspondence:}

Dr. Neeru Sahni, Department of Anaesthesia and Intensive Care,

PGIMER, Chandigarh - 160 012, India.

E-mail: neerunalin@yahoo.com

\begin{tabular}{|l|l|}
\hline \multicolumn{2}{|c|}{ Access this article online } \\
\hline Quick Response Code: & Website: \\
\hline & www.jnaccjournal.org \\
\cline { 2 - 2 } & \\
\hline & \\
\hline
\end{tabular}

opioids instead of morphine. ${ }^{[1,2]}$ As morphine is still commonly used in the practice of neuroanaesthesia especially in developing countries, we designed this retrospective study to compare the time to emergence with morphine when compared to fentanyl in patients undergoing supratentorial tumor surgery.

\section{MATERIALS AND METHODS}

Following institute ethics committee approval, the emergence data of a published study using fentanyl was retrospectively compared to our centre (from June 2008 to May 2013) where morphine is predominantly used. ${ }^{[3]}$ The study included patients of either sex, aged 20-60 years with full pre-operative Glasgow coma score undergoing elective craniotomy for supratentorial tumours. As one of the authors of the previous study was also involved in analysing this retrospective data, only those patients

This is an open access article distributed under the terms of the Creative Commons Attribution-NonCommercial-ShareAlike 3.0 License, which allows others to remix, tweak, and build upon the work non-commercially, as long as the author is credited and the new creations are licensed under the identical terms.

For reprints contact: reprints@medknow.com

How to cite this article: Bhagat $\mathrm{H}$, Sahni $\mathrm{N}$, Bhukal I, Khanna $\mathrm{P}$, Bastola P, Bithal PK, et al. Comparative evaluation of morphine and fentanyl for emergence following supratentorial craniotomy. J Neuroanaesthesiol Crit Care 2017;4:155-8. 
were included in the retrospective study group which had similar anaesthetic plan as in the previous study. The patients who had been subjected to similar emergence protocol (low-dose propofol along with nitrous oxide in oxygen) were included in the study. The anaesthesia and emergence technique of the patient included in the study has been described in Table 1. Patients with ischaemic and/or congestive heart disease, hypertension, chronic obstructive pulmonary disease, diabetes mellitus and hepatic and renal dysfunction and the patients who could not be extubated due to intraoperative surgical complications were excluded from the study.

The patients of morphine group (Group M) received single dose morphine $0.1 \mathrm{mg} / \mathrm{kg}$ before induction and additional boluses of morphine $1.5-3 \mathrm{mg}$ as per requirement. The fentanyl group (Group F) received $2 \mathrm{mcg} / \mathrm{kg}$ body weight fentanyl at induction, $1 \mathrm{mcg} / \mathrm{kg}$ before skin incision and at the beginning of dural closure. Fentanyl $1 \mathrm{mcg} / \mathrm{kg}$ was given as additional dose whenever required. Following head dressing, the trachea was extubated after adequate reversal of residual neuromuscular blockade with neostigmine $0.05 \mathrm{mg} / \mathrm{kg}$ and glycopyrrolate $0.01 \mathrm{mg} / \mathrm{kg}$ once the patients opened eyes or responded to verbal commands. Thereafter, the patients were moved to the recovery room.

Emergence from anaesthesia was defined as the interval between completion of head dressing (when nitrous oxide was discontinued) and extubation. The patients who were extubated within $15 \mathrm{~min}$ after completion of dressing were considered to have had early emergence. The haemodynamics and immediate post-operative characteristics were also noted.

Means of normally distributed data were compared using Student's $t$-test for two groups. For time-dependent changes repeated measure, ANOVA was applied. Proportions were compared using Chi-square or Fisher's exact test, and all statistical tests were two-sided and were performed at a significance level of $\alpha=0.05$. A multicollinearity diagnosis was done using the same regression technique and duration of anaesthesia and duration of surgery were found to be highly correlated.

\section{RESULTS}

Of total 84 patients included in the study, 37 patients were there in Group M while Group F had 47 patients. Demographic and intraoperative characteristics did not differ between the groups [Table 2]. Emergence time and number of patients with early emergence were comparable in both groups [Table 3]. The duration of anaesthesia was significantly higher in the fentanyl group. A standard regression analysis was performed to explore the relation between the duration of anaesthesia, temperature and end-tidal carbon dioxide with emergence time. The unique contribution made by the duration of anaesthesia $(\beta=0.132)$, temperature $(\beta=-0.143)$ and end-tidal carbon dioxide $(\beta=-0.132)$ was found to statistically insignificant in all the cases. Figures 1 and 2 compare the heart rate and blood pressure between the two groups. The heart rate and mean arterial pressure were comparable in both groups at all time points.

\section{DISCUSSION}

One of the important concerns with the use of long-acting opioids is that of probable delayed emergence from anaesthesia. The present study retrospectively evaluated and compared the time to the emergence in patients undergoing supratentorial tumor surgery using either morphine or fentanyl. The study did not find any significant difference in time to emergence with the use of morphine when compared to fentanyl. Morphine has an elimination half-life of around $120 \mathrm{~min}$. Considering the average duration of surgery in supratentorial craniotomy to be $3-4 \mathrm{~h}$ and elimination half-life to be similar it would not be unreasonable to use morphine. In contrast, due to shorter duration of action of fentanyl, it needs to be administered repeatedly whereas morphine can be used as a bolus dose. In resource constrained centres, the use of morphine would perhaps help in reducing the cost.

In a study, comparing remifentanil with fentanyl for post-operative recovery following supratentorial craniotomy, the use of morphine in remifentanil group

Table 1: Anaesthesia technique

\begin{tabular}{lll}
\hline & Morphine & Fentanyl \\
\hline Induction & Morphine $0.1 \mathrm{mg} / \mathrm{kg}$ & Fentanyl $2 \mathrm{ug} / \mathrm{kg}$ \\
& Thiopentone $4-6 \mathrm{mg} / \mathrm{kg}$ & Thiopentone $4-6 \mathrm{mg} / \mathrm{kg}$ \\
Maintenance & Propofol/isoflurane & Propofol/isoflurane \\
& $60 \% \mathrm{~N}_{2} \mathrm{O}$ in $\mathrm{O}_{2}$ & $60 \% \mathrm{~N}_{2} \mathrm{O}$ in $\mathrm{O}_{2}$ \\
& Vecuronium $/ \mathrm{morphine}$ & Vecuronium/fentanyl \\
Beginning of dural closure & IV propofol 3 mg/kg/h & IV propofol 3 mg/kg/h \\
Completion of skin sutures & Propofol infusion stopped & Propofol infusion stopped \\
Skull pin removal & Nitrous oxide off & Nitrous oxide off \\
\hline
\end{tabular}

IV=Intravenous 
Table 2: Demographic profile and intraoperative characteristics

\begin{tabular}{lccc}
\hline & Morphine $(\boldsymbol{n = 3 7})$ & Fentanyl $(\boldsymbol{n}=\mathbf{4 7})$ & $\boldsymbol{P}$ \\
\hline Age (years) & $41 \pm 13$ & $40 \pm 11$ & $31 / 16$ \\
Sex (male/female) & $23 / 14$ & $62 \pm 9$ & 0.76 \\
Weight (kg) & $67 \pm 13$ & $7 / 29 / 11$ & 0.72 \\
Tumor type M/G/O & $10 / 25 / 2$ & $7 / 11 / 9 / 20$ & 0.05 \\
Mass effect N/M/M/S & $1 / 10 / 13 / 13$ & $5 \pm 2$ & 0.13 \\
Maximum tumor diameter (cm) & $5 \pm 2$ & $5.7 \pm 5.8$ & 0.53 \\
Midline shift (mm) & $6.1 \pm 6$ & $246 \pm 67$ \\
Duration of anaesthesia (min) & $193 \pm 65$ & 261 \\
Opioid used (mg/ug) & 6.5 & 0.76 \\
\hline
\end{tabular}

Values are mean $\pm \mathrm{SD}$ or number of patients. M/G/O=Meningioma/glioma/others, N/M/M/S=None/mild/moderate/severe, $S D=S t a n d a r d ~ d e v i a t i o n$

Table 3: Emergence and post-operative characteristics

\begin{tabular}{lccc}
\hline & Morphine $(\boldsymbol{n}=\mathbf{3 7})$ & Fentanyl $(\boldsymbol{n}=\mathbf{4 7})$ & $\boldsymbol{P}$ \\
\hline Emergence time (min) & $8.5 \pm 3.7$ & $7.8 \pm 5.1$ & 0.11 \\
Early emergence $(\leq 15 \mathrm{~min})$ & $33(89)$ & $43(98)$ & 0.20 \\
Hypoventilation & 0 & 0 & \\
Reintubation & 0 & 0 & 0.37 \\
Convulsions & 0 & $1(2)$ & \\
\hline
\end{tabular}

Values are mean \pm SD or number of patients $(\%)$. SD=Standard deviation

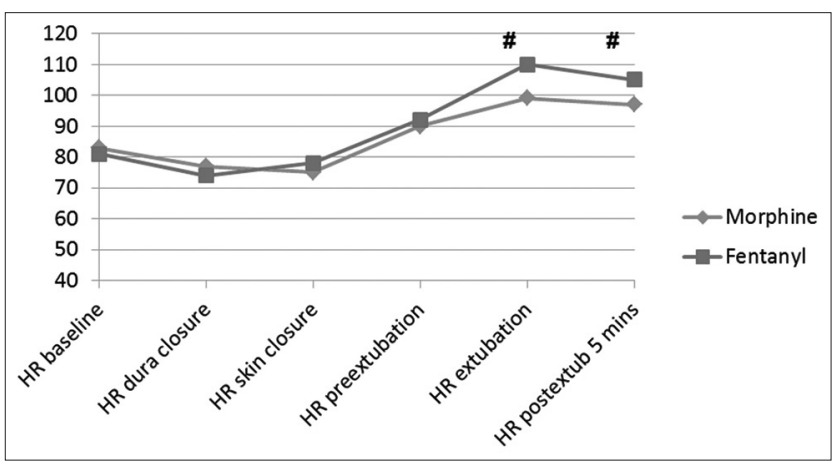

Figure 1: Heart rate at various time points

as transitional analgesia was observed to shorten neurological recovery compared to fentanyl without compromising the quality of recovery. ${ }^{[4]}$ A dose of $100 \mathrm{mcg}$ is approximately equivalent in analgesic activity to $10 \mathrm{mg}$ of morphine, and the mean dose of morphine used in our study is approximately 2.5 times the equivalent dose of fentanyl. Despite this, the emergence was not affected, and it appears that the concern of delayed emergence is overemphasised. Morphine and fentanyl have been compared in pre-hospital settings in spontaneously breathing patients, and authors observed equal efficacy and similar adverse effects. ${ }^{[5,6]}$ Another study comparing morphine and fentanyl in out-of-hospital setting observed similar analgesia and no difference in adverse effects with the use of both the agents. ${ }^{[7]}$ We also did not observe any incidence of

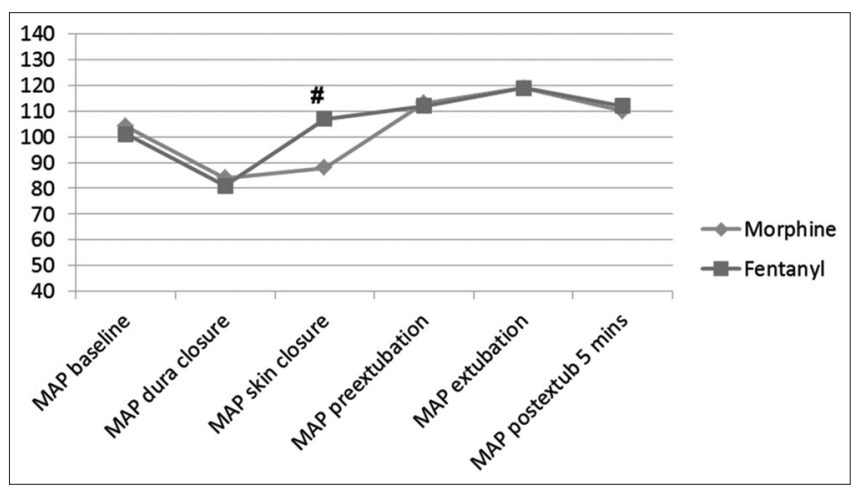

Figure 2: Mean arterial pressure at various time points

post-operative respiratory complications with either morphine or fentanyl.

Although Bilotta et al. concluded that remifentanil and sufentanil were suitable for fast-track neuroanaesthesia, Magni et al. found no difference in emergence time between fentanyl and remifentanil in patients undergoing craniotomy for supratentorial intracranial surgery ${ }^{[8,9]}$ It appears that it is usually the traditional prejudice against opioids that prevents its use.

\section{CONCLUSION}

The retrospective nature and no control of the test drug used are the limitations of the present study. The absence of an assessment of anaesthetic depth is 
a drawback, but the doses used are consistent with common clinical practice. Thus, our study demonstrates that the emergence from anaesthesia is similar with the use of either morphine or fentanyl. A large prospective randomised control trial would be required to merit strong recommendations for the preference of opioids in neurosurgical patients.

\section{Financial support and sponsorship Nil.}

\section{Conflicts of interest}

There are no conflicts of interest.

\section{REFERENCES}

1. Guy J, Hindman BJ, Baker KZ, Borel CO, Maktabi M, Ostapkovich $\mathrm{N}$, et al. Comparison of remifentanil and fentanyl in patients undergoing craniotomy for supratentorial space-occupying lesions. Anesthesiology 1997;86:514-24.

2. Balakrishnan G, Raudzens P, Samra SK, Song K, Boening JA, Bosek V, et al. A comparison of remifentanil and fentanyl in patients undergoing surgery for intracranial mass lesions. Anesth Analg 2000;91:163-9.

3. Bhagat H, Dash HH, Bithal PK, Chouhan RS, Pandia MP. Planning for early emergence in neurosurgical patients: A randomized prospective trial of low-dose anesthetics. Anesth
Analg 2008;107:1348-55.

4. Gelb AW, Salevsky F, Chung F, Ringaert $K$, McTaggart-Cowan RM, Wong $\mathrm{T}$, et al. Remifentanil with morphine transitional analgesia shortens neurological recovery compared to fentanyl for supratentorial craniotomy. Can J Anaesth 2003;50:946-52.

5. Smith MD, Wang Y, Cudnik M, Smith DA, Pakiela J, Emerman CL. The effectiveness and adverse events of morphine versus fentanyl on a physician-staffed helicopter. J Emerg Med 2012;43:69-75.

6. Galinski M, Dolveck F, Borron SW, Tual L, Van Laer V, Lardeur JY, et al. A randomized, double-blind study comparing morphine with fentanyl in prehospital analgesia. Am J Emerg Med 2005;23:114-9.

7. Fleischman RJ, Frazer DG, Daya M, Jui J, Newgard CD. Effectiveness and safety of fentanyl compared with morphine for out-of-hospital analgesia. Prehosp Emerg Care 2010;14:167-75.

8. Bilotta F, Caramia R, Paoloni FP, Favaro R, Araimo F, Pinto $G$, et al. Early postoperative cognitive recovery after remifentanil-propofol or sufentanil-propofol anaesthesia for supratentorial craniotomy: A randomized trial. Eur J Anaesthesiol 2007;24:122-7.

9. Magni G, Baisi F, La Rosa I, Imperiale C, Fabbrini V, Pennacchiotti ML, et al. No difference in emergence time and early cognitive function between sevoflurane-fentanyl and propofol-remifentanil in patients undergoing craniotomy for supratentorial intracranial surgery. J Neurosurg Anesthesiol 2005; 17:134-8. 